
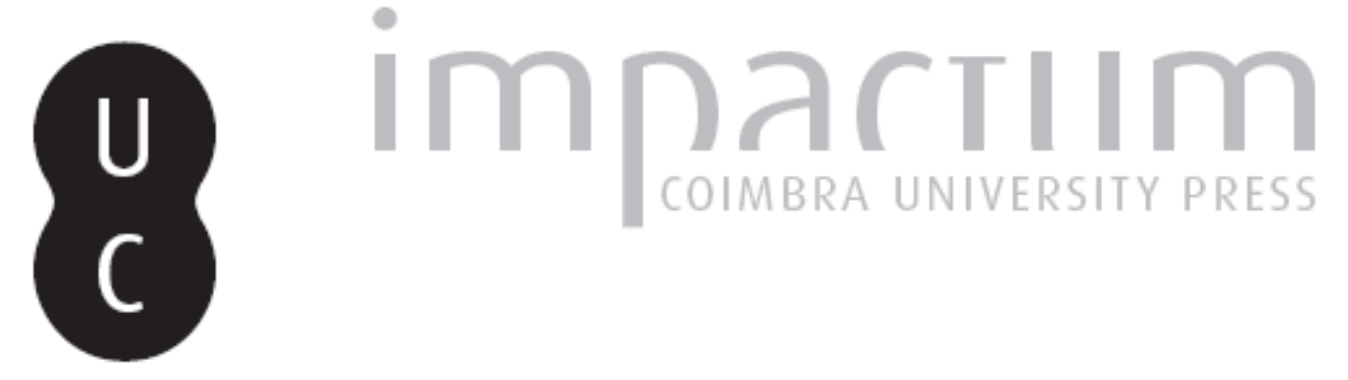

\title{
[Recensão a] Pimentel, M. R. (coord.) 2001. Portugal e Brasil no advento do mundo moderno: sextas Jornadas de História Ibero-Americana
}

Autor(es): $\quad$ Areia, Manuel Laranjeira Rodrigues de

Publicado por: CIAS - Centro de Investigação em Antropologia e Saúde

URL

persistente:

URI:http://hdl.handle.net/10316.2/41287

DOI:

DOI:http://dx.doi.org/10.14195/2182-7982_18_15

Accessed : $\quad$ 26-Apr-2023 10:26:28

A navegação consulta e descarregamento dos títulos inseridos nas Bibliotecas Digitais UC Digitalis, UC Pombalina e UC Impactum, pressupõem a aceitação plena e sem reservas dos Termos e Condições de Uso destas Bibliotecas Digitais, disponíveis em https://digitalis.uc.pt/pt-pt/termos.

Conforme exposto nos referidos Termos e Condições de Uso, o descarregamento de títulos de acesso restrito requer uma licença válida de autorização devendo o utilizador aceder ao(s) documento(s) a partir de um endereço de IP da instituição detentora da supramencionada licença.

Ao utilizador é apenas permitido o descarregamento para uso pessoal, pelo que o emprego do(s) título(s) descarregado(s) para outro fim, designadamente comercial, carece de autorização do respetivo autor ou editor da obra.

Na medida em que todas as obras da UC Digitalis se encontram protegidas pelo Código do Direito de Autor e Direitos Conexos e demais legislação aplicável, toda a cópia, parcial ou total, deste documento, nos casos em que é legalmente admitida, deverá conter ou fazer-se acompanhar por este aviso.

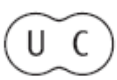


Antropologia Portuguesa

Volume $18 \cdot 2001$

Departamento de Antropologia | Universidade de Coimbra 
Pimentel, M. R. (coord.) 2001. Portugal e Brasil no Advento do Mundo Moderno: sextas Jornadas de História Ibero-Americana, Portimão, 2000. Lisboa, Edições Colibri. 392 p. ISBN 972-772-238-5.€ 20,95.

As Comunicações das Sextas Jornadas de História Ibero-Americana, subtítulo do livro em referência, realizadas em Portimão de 4 a 6 de Maio de 2000, apresentam-se neste volume agrupadas sob três epígrafes, a saber: Homens e construções de espaços; Novas sociedades e circuitos atlânticos; Trocas culturais. O conjunto remata com uma interessante conferência de M. R. Pimentel, a coordenadora da publicação e também do evento, sobre o tema: El-rei do Congo em Portugal e no Brasil. Da realidade à ficção.

Não podendo referir-me explicitamente a cada uma das vinte comunicações que integram a publicação permito-me destacar alguns aspectos que no correr da leitura me surpreenderam ou pelo conteúdo ou pelo contexto ou pela sensibilidade do tema. Assim, começaria por destacar a ligação a África, e particularmente a Angola, com os textos de M.A. Amorim (Portugal na imprensa oitocentista de Angola - a colonização de Moçâmedes por luso-brasileiros) e o já referido texto de M.R. Pimentel (El-rei do Congo em Portugal e no Brasil. Da realidade à ficção).

Do primeiro há a destacar a colonização de Moçâmedes por repatriados portugueses empurrados por ondas de lusofobia em diferentes cidades do Brasil, particularmente no Pará. O mito de Angola como "novo Brasil" desenvolvido depois da independência da grande colónia brasileira vê-se assim reforçado, a par de muitos elementos culturais comuns nas comunidades dos dois lados do Atlântico veiculados por milhares de escravos transportados de Angola para o Brasil. Este movimento inverso de portugueses que voltam do Brasil não para Portugal mas para Angola mostra a constante triangulação Europa-África-Brasil que vem dos primórdios da colonização brasileira. Aqui aflora-se também a questão da inversão histórica entre colono e colonizado sendo que o português, antigamente categorizado como colono, vê-se agora como que impelido para o trabalho no sertão (trabalho escravo) ou, em alternativa, retira para Angola. $O$ facto de Pinheiro Chagas, na altura, denunciar a intenção de substituir a escravatura negra pela escravatura branca é bem significativo.

A outra nota africana, e no caso também angolana, é a instituição do "Rei do Congo" (p. 371-392) que, por um lado, mostra o indiscutível "peso 
africano na sociedade colonial" (p. 378) e, por outro, o investimento, até ao limite, dos afro-brasileiros nas práticas simbólicas que os faziam reviver África. Mesmo escravos, desenraizados, e tratados como "plebe ínfima da Baia" (p. 382), a população negra investe nas práticas simbólicas de que a instituição "Rei do Congo", ou congada, é certamente um dos grandes expoentes. Muitos espiritos de "pretos velhos" evocados nos rituais de Candomblé e Umbanda, tais como Juca Rosa, Felisberto de Cabinda, Maria d'Aruanda, mãe conga, etc. são outras tantas expressões que evocam o mundo simbólico dos antepassados.

Outro aspecto que gostaria de destacar no conjunto das comunicações e que atravessou por longos tempos todas as camadas da sociedade portuguesa (metrópole e colónias) é o medo, quase obsessivo, de traições à fé, dos cristãos novos, quase sempre entendidos como cristãos vindos do judaísmo mas sem excluir os cristãos novos de mouros, temas explicitamente abordados nos textos de I. Monteiro (A primeira visitação do Santo Oficio a terras do Brasil) e de R. Ribas (Festas e Inquisição: os mouriscos na cristandade portuguesa de quinhentos).

O medo da "maldita seita de Mafoma" vai a par do receio dos "...muitos que fugiram do Brasil, lugar de degredo e asilo...e ai reforçaram os laços da nação..." (seja judaica seja muçulmana) pelo que muitos sendo “...senhores de engenho e homens de negócios..." são simultaneamente “...homens de comunhão e de sinagoga." (p. 278).

Para cuidar de uns e de outros, a Santa Inquisição, nascida do imenso medo que domina a sociedade da época, trabalha activamente e nada passa desapercebido ao olhar atento do grande Inquisidor.

Se os cristãos novos de mouros são detectados no "...carneiro degolado voltado para Alquibela que é para onde nasce o sol" (p. 53), já os outros, os cristãos de judeus, muito mais numerosos, há que os procurar em todas as partes do Reino, sem excluir a grande colónia do Brasil e também Angola "...terra sadia e com Religiosos de que se pode (o Inquisidor) ajudar com Jurisdição sobre o Congo, Ilha do Príncipe e São Tomé que estão cheias de cristãos novos" (p. 272). Era preciso sobretudo ter em conta, como alertava o Provincial dos Jesuitas, Pedro Rodrigues (1591), “...que também a Guiné (como o Brasil) convidava à liberdade de palavras e costumes" (p. 274); e esta espécie de tropicalização das consciências, que a todos atingia, tomava até formas de espavento que chocaram o P. Fernão Cardim que já em 1581 denunciava os excessos dos muitos vianeses da 
cidade de Pernambuco pois "...vestem-se e as mulheres e os filhos de toda sorte de veludos, damascos e outras sedas e nisto têm grandes excessos.". O perigo tropical era óbvio e Cardim não deixa de observar: "As mulheres são muito senhoras e não muito devotas..." (p. 276).

Os medos eram mais que muitos mas acima de todos estava o do Demónio infiltrando-se na comunidade dos crentes, primeiro através de mouros, judeus e turcos, e mais tarde através de índios e de negros.

Apesar da omnipresença diabólica e da sua permanente ameaça à fé dos crentes a natureza do solo brasileiro era pródiga, como testemunhavam as plantas e os animais. O texto de F. Cristovão (As frutas brasileiras e sua significação oculta) dá-nos conta desse aspecto, quase sedutol; das frutas brasileiras carregadas de poderes misteriosos. Alguns viram na riqueza do solo "...o remédio dos pobres;" de Portugal (Gândavo) mas é sobretudo a diversidade das frutas e o esplendor da vegetação luxuriante que evocam a imagem do paraiso; até a flor do martírio (maracujá) está presente (p. 288)! Tudo leva vantagem ao que se vê em Portugal, só o macaco-preguiça é que parece desprestigiar o Brasil já que "...enquanto dá só dois passos, pode o homem dar três mil...". Mais um indício do "perigo tropical" que não pode deixar de ser anatematizado:

\author{
"Maldito este bicho seja \\ que tão mau costume tem \\ pois dele o nome nos vem \\ da priguiça do Brasil" (p. 295).
}

Mas feitas bem todas as contas o saldo é francamente positivo (texto de S. Castro: A carta de Pero Vaz de Caminha e o lusotropicalismo utópico) já que o "gentio branco" (expressão de Oliveira Martins) conseguiu "...viver com a melhor naturalidade a integração sexual e sentimental..." (p. 299) enraizando assim, e ao que se crê para sempre, o sincretismo cultural, o que não é pouco, o qual já se anunciava na Carta de Pero Vaz de Caminha que haveria de ficar para a história como o documento fundador do "lusotropicalismo utópico" (p. 30l), o único que temos porque outro não há.

\title{
Manuel Laranjeira Rodrigues de Areia
}

Departamento de Antropologia

Universidade de Coimbra

3000-056 Coimbra, Portugal

areia@ci.uc.pt 